\title{
Sociología
}

Schlack Soto, M. F. (2019). Hacia un modelo de gestión local del cambio climático. Revista de Sociología, 34(1), 61-80. doi: 10.5354/0719-

\section{Hacia un modelo de gestión local del cambio climático}

\author{
[Towards a local model of management regarding climate change] \\ Miguel Felipe Schlack Soto (i) \\ Universidad de Chile ${ }^{1}$
}

\begin{abstract}
Resumen
Este trabajo caracteriza las reflexividades que construyen los Municipios Integrantes de la Red Chilena de Municipios ante el Cambio Climático en la Región Metropolitana sobre las consecuencias del cambio climático en sus respectivos territorios. La evidencia empírica, lograda por medio de entrevistas semiestructuradas y analizada a través de la técnica de análisis de contenido, entregó como resultado que las impresiones municipales sobre el fenómeno socioambiental y sus modos de abordaje están determinadas por los efectos particulares que genera en los diferentes territorios, y por el ambientalismo y ecologismo como referentes de sentido. Asimismo, se encontraron débiles convergencias entre municipios e instituciones del gobierno central y que el cambio climático profundiza las desigualdades socioterritoriales ya existentes en la Región Metropolitana.
\end{abstract}

Palabras clave: cambio climático, gobiernos locales, convergencias institucionales, ambientalismo, ecologismo.

\begin{abstract}
This work characterize the reflexivities in which the municipalities, integrating the Chilean Municipalities Network against Climate Change in the Metropolitan Region, construct about the consequences regarding climate change in their respective territories. The empirical evidence, gathered by semi-structured interviews, and examined through Content Analysis, deliver results that the municipal impressions regarding the socioenvironmental phenomena, and their ways to approach it, are determined by the particular effects produced inside the different areas, along with Environmentalism and Ecologism as models of meaning. Likewise, evidence showed the existence of weak convergences between Municipalities and Central Government Institutions, and also that Climate Change deepens the socio-territorial inequalities already existent in the Metropolitan Region.
\end{abstract}

Keywords: climate change, local governments, institutional convergences, environmentalism, ecologism.

1 El trabajo presentado fue realizado en la Universidad de Chile. Actualmente el autor se encuentra en la Universidad de Santiago de Chile y la Universidad Católica Silva Henríquez.

Contacto: La comunicación sobre este artículo debe ser enviada a Miguel Felipe Schlack Soto, email: miguel.schlack@usach.cl

Financiamiento: Programa Atracción e Inserción de Capital Humano Avanzado (PAI) de la Comisión Nacional de Investigación Científica y Tecnológica (CONICYT-PAI 82140012, IR. Rodolfo Sapiains). 

gestión local del cambio climático. Revista de Sociología, 34(1), 61-80. doi: 10.5354/0719-

\section{INTRODUCCIÓN}

En las actuales sociedades impactadas por el cambio climático, es posible identificar dinámicas de reflexividad (Beck, 1998) que inducen a la creación de instituciones públicas con el fin de abordar el fenómeno socio ambiental del cambio climático. En el caso Chile, este proceso ha sido gradual y comienza desde la ratificación por parte del Estado del Convenio Marco de Naciones Unidas para el Cambio Climático en 1994.

De hecho, la concreción de instituciones de Estado y de planes gubernamentales que asuman el cambio climático como un problema público y de desarrollo (Blanco \& Fuenzalida, 2013), se relaciona con el reconocimiento de los efectos que tal problema socio ambiental genera en la sociedad y en los ecosistemas (Beck, 2008). En cualquier caso, a esta concreción, le preceden ejercicios de reflexión sobre los déficits de gobernabilidad, (Arnold \& Urquiza, 2010), que demuestran que la institucionalidad impediría asumir el cambio climático e intermediar en los conflictos sociales que adquieren fuerza por dicho problema y se ven agudizados por las repercusiones que ha significado la mantención de una estrategia de crecimiento económico neoliberal.

Desde el Panel Intergubernamental de Expertos ante el Cambio Climático (IPCC, 2018) se ha recomendado que la disminución de la aceleración del cambio climático debe ir acompañado de estrategias de desarrollo institucional local que promuevan capacidades territoriales para enfrentar las vulnerabilidades locales. Por tanto, para impulsar un abordaje del cambio climático son necesarias estrategias de convergencias, entendiendo por esto que "la política del cambio climático coincida en un sentido positivo con otros valores y objetivos políticos" (Giddens, 2010, p.19). Es en relación con esto que las estrategias de convergencia serían la concreción de objetivos comunes entre instituciones centrales y locales de gobierno.

Así también, en el proceso de institucionalización del cambio climático en Chile, han destacado: (i) las Estrategias Nacionales del Cambio Climático, (ii) los Planes de Acción del Cambio Climático y (iii) el Comité Asesor del Cambio Climático. Entre el conjunto de las medidas definidas, se ha señalado que la adaptación y mitigación del fenómeno socio ambiental expuesto, requiere de las señaladas estrategias de coordinación intrainstitucional, como también de la construcción de objetivos comunes entre el Estado y el mundo privado. Asimismo, en el año 2015, en la Conferencia de las Naciones Unidas Sobre Cambio Climático (COP 21), el Estado de Chile se comprometió a disminuir un $30 \%$ las emisiones de gases de efecto invernadero que el país genera, para lo cual el fortalecimiento de estos vínculos se convierte un elemento de marcada relevancia. Chile durante 2019 será el organizador de la próxima reunión de la Conferencia de las Naciones Unidas sobre Cambio climático (COP 25), lo que plantea nuevos desafíos y urgencias para fortalecer los 
Schlack Soto, M. F. (2019). Hacia un modelo de gestión local del cambio climático. Revista de Sociología, 34(1), 61-80. doi: 10.5354/0719529X.2019.54268

procesos de convergencia. Por ello, el abordaje del cambio climático desde los gobiernos locales enfrenta dificultades para gestionar una gobernanza climática, en función de la orgánica estructural actual de los municipios, sus posibilidades de relación con otras instituciones de Estado y la serie de condicionantes que derivan del ambientalismo como corriente de pensamiento medio ambiental que reestructura el accionar público.

Entonces, caracterizar y describir las reflexividades que construyen los funcionarios de los Municipios Integrantes de la Red Chilena de Municipios ante el Cambio Climático, en la Región Metropolitana, constituye un objeto de investigación esencial desde una sociología que asume el cambio climático como asunto científico y político. A su vez, el rol de las ciencias sociales se torna esencial, en la medida que Chile, como nación altamente vulnerable ante los efectos del fenómeno socio ambiental expuesto, requiere urgentemente de conocimientos sobre el accionar de las instituciones de Estado y el obstáculo que estas presentan para hacer frente al problema. Esta investigación estuvo centrada en el discurso de funcionarios municipales directamente vinculados con las acciones relacionadas a la reducción del cambio climático y la prevención y mitigación de sus consecuencias.

El rol municipal

La institucionalización nacional de la política del cambio climático ha sido un proceso que se ha desarrollado desde diversos niveles de gobernanza, y los gobiernos locales también se han adentrado a asumir el fenómeno climático. La política climática ejercida desde estas mismas instituciones locales ha contribuido al abordaje territorial del cambio climático para enfrentar las vulnerabilidades e inequidades sociales que el fenómeno produce (De Castro, Hogenboom \& Baud, 2015). En los compromisos que Chile ha suscrito ante la Convención Marco de Naciones Unidas, se postula que la gobernanza local del cambio climático es primordial para el cumplimiento de las metas de reducción de emisiones de gases de efecto invernadero. Por tanto, gobiernos locales deben construir, social y ambientalmente, infraestructuras de gestión para impulsar planificación y políticas de cambio climático.

Algunos municipios en Chile han sido pioneros de este proceso, abordando el cambio climático desde las peculiaridades de su territorio y proyectando prácticas hacia otros instituciones centrales y locales de Estado. Este proceso ha sido conflictivo puesto que existen estructuras y normas de gestión municipal que son rígidas y que constituyen obstáculos para trabajar las temáticas ambientales (Rungrauangsakorn \& Jara, 2012). Algunas serían la precarización laboral, el limitado interés de los alcaldes, poca preparación técnica-profesional e ineficientes jerarquías administrativas para posicionar los asuntos medio ambientales en la gestión municipal.

Otros aspectos que inciden en el trabajo municipal sobre el cambio climático son la limitada coordinación intersectorial entre los municipios y las redes de apoyo provenientes de organizaciones no gubernamentales, 
Schlack Soto, M. F. (2019). Hacia un modelo de gestión local del cambio climático. Revista de Sociología, 34(1), 61-80. doi: 10.5354/0719529X.2019.54268

universidades, ministerios e institucionales internacionales (Fernández, 2010). En relación a estas débiles acciones intersectoriales, estas dependerán de su interacción con gobernaciones provinciales, intendencias y ministerios, por lo cual, hay una realidad desigual $\mathrm{y}$, en algunos casos conflictiva, en la relación que un municipio puede establecer con alguna institución como, por ejemplo, el Ministerio del Medio Ambiente. Esto mostraría que la coordinación, reconocida como esencial instrumento del Estado para el Plan Nacional de Acción del Cambio Climático 2017-2022 (PANCC-II), no estaría siendo efectivamente fortalecida.

En América Latina, los modelos de gestión local están insertos en contextos político neoextractivistas, de sobre explotación de recursos naturales (Gudynas, 2011). En Chile, este fenómeno se materializa en ejemplos como, la apropiación privada de forestales y empresas agrícolas de un recurso eco sistémico esencial como el agua, el que estructurado constitucionalmente ha permitido el dinamismo económico de dichos sectores, mermando así las posibilidades de subsistencia de variadas comunidades urbanas y rurales. Por ello, las vulnerabilidades que produce el cambio climático se profundizan, proyectando nuevas inequidades territoriales y conflictividad social (Aliste, 2010; Aliste \& Stam, 2016). En consecuencia, los modelos de gobernanza local requieren de estrategias de superación de la pobreza, de promoción de nuevos modelos de desarrollo y generación de justicia social para así superar los conflictividades socio-ambientales (De Castro, Hogenboom \& Baud, 2015).
Tales modelos de gobernanza deben ser conducentes a modos de gestión que promuevan la coordinación con la ciudadanía desde un enfoque vinculante, para así concretar una mejor distribución de poder, posibilitando una incidencia de los actores locales en la distribución de los recursos naturales y determinando las prioridades de gobernanza ambiental (De Castro, Hogenboom \& Baud, 2015). Tal forma de concebir la gobernanza, desde los valores de la justicia climática y la promoción derechos, conecta con las sensibilidades que el ecologismo ha construido como respuesta ante las crisis socio ambientales (Aldunate, 2001; Dobson, 1997). Sin embargo, la gobernanza ambiental ha asumido preponderantemente aquellos criterios cercanos al ambientalismo, desde los cuales el abordaje del cambio climático debe operar con criterios de estrategia de gestión, prescindiendo de la consideración de los asuntos medio ambientales como problemas políticos y generadores de inequidades territoriales (De Castro, Hogenboom \& Baud, 2015).

Corrientes de pensamiento ambiental: ambientalismo y ecologismo

La identificación de directrices provenientes del ambientalismo o el ecologismo es esencial para comprender el abordaje que del cambio climático realizan los gobiernos locales en Chile. Por ello, es de utilidad profundizar sobre estas corrientes, en la medida que han estructurado las ideas sobre como una sociedad debe asumir los asuntos 
Schlack Soto, M. F. (2019). Hacia un modelo de gestión local del cambio climático. Revista de Sociología, 34(1), 61-80. doi: 10.5354/0719529X.2019.54268

socio ambientales, y que es posible de evidenciar en los discursos que construyen los municipios.

Estas dos corrientes de pensamiento socioambiental se diferencian de las otras ideologías de la modernidad, debido a la consideración del medio ambiente como espacio que, al ser destruido por la acción antropogénica genera efectos adversos en la sociedad (Dobson, 1997). Sin embargo, a pesar de compartir objetivos comunes de reducción el impacto socio ambientales, sus diagnósticos y propuestas difieren entre sí (Riechman \& Fernández, 1994). Por un lado, el ambientalismo y sus propuestas para revertir una crisis socio ecológica como el cambio climático se sustentan en "una aproximación administrativa a los problemas medio ambientales, convencida de que pueden ser resueltos sin cambios fundamentales en los actuales valores o modelos de producción y consumo" (Dobson, 1997, p. 22). Por tanto, el ambientalismo ha centrado el abordaje del cambio climático sin concretar modificaciones sustantivas a los patrones de crecimiento económico y desconsiderando establecer un modelo de sociedad diferente para enfrentar una crisis ecológica. Son tales formas de superar la crisis ecológica las que conformaron las directrices del ambientalismo en Chile (Aldunate, 2001). El ambientalismo como un modelo de relación sociedad-naturaleza se ha adecuado a una nueva forma de capitalismo, el que, como economía verde o reformismo ambiental, promueve métodos de producción limpia (Aldunate, 2001). La economía verde del ambientalismo implica la expansión de las lógicas de mercado, primando los referentes de crecimiento económico y agilización de mercados para desarrollar ventajas productivas ante la crisis ecológica.

El ecologismo es una corriente de pensamiento ambiental que, al igual que el ambientalismo, tiene sus orígenes en la década de los setenta. Este cuerpo de ideas tiene como punto de partida lo acontecido en la Cumbre del Ambiente Humano del año 1972 desarrollada en Estocolmo. En tal contexto, el ecologismo plantea que los lineamientos técnicos y de gestión institucional que se consagran en la cita de Estocolmo son inadecuados para materializar políticas ambientales que permitan transformar la sociedad (Aldunate, 2001); y sostendrá que la superación de las crisis pasa por la conformación de una nueva relación sociedad-naturaleza, la que se lograría por medio de una trasformación cultural profunda. Implicando así la superación de las representaciones simbólicas que han comprendido a la naturaleza como un mundo natural que debe ser sometido para lograr el bienestar de la sociedad (Dobson, 1997).

En síntesis, para superar las crisis ecológicas, el ecologismo plantea profundos cambios en la organización de la sociedad y en las actitudes hacia el mundo natural no humano, dando cuanto que los problemas medio ambientales proyectan escenarios de inequidad $\mathrm{y}$ precarización, que se relacionan con las dinámicas propias de un capitalismo que visualiza la naturaleza como mercancía que debe explotarse para procurar crecimiento económico (Beck, 1998). Las sensibilidades ecologistas cuestionan con mayor radicalidad tales prácticas económicas y políticas que han sostenido el 
Schlack Soto, M. F. (2019). Hacia un modelo de gestión local del cambio climático. Revista de Sociología, 34(1), 61-80. doi: 10.5354/0719529X.2019.54268

crecimiento económico y que no consideran la condición finita de los recursos naturales (Aldunate, 2001).

La tensión entre ecologismo y el ambientalismo se ha producido en atención a qué modelos de sociedad-naturaleza son los adecuados para revertir la crisis ecológica (Riechman \& Fernández, 1994). Estas corrientes influencian las propuestas para superar la crisis del cambio climático en Chile y, el ambientalismo determina el entendimiento que el Estado hace del cambio climático (Blanco \& Fuenzalida, 2013). Ambientalismo y ecologismo son pensamientos no herméticos, en la medida que este último ha evolucionado hacia el ecologismo social, el que plantea que los daños ecológicos están determinados por factores de explotación de clase e inequidad en el uso de los recursos naturales. A su vez, el ambientalismo ha transitado hacia un ambientalismo neoliberal que argumenta la conveniencia de la propiedad privada como forma de protección socio ambiental (Aldunate, 2001).

\section{El ambientalismo institucional en Chile}

De los análisis de Aldunate (2001), como también de Blanco y Fuenzalida (2013), es posible aseverar que la gobernanza ambiental desde el Estado de Chile, ha asumido el cambio climático través de lineamientos del ambientalismo, viabilizando así instrumentos de mercado y limitadas regulaciones económicas que impactan en el abordaje del cambio climático que los gobiernos locales pueden concretar. Por ello, en el análisis de la sociología sobre el cambio climático debe estar presente una flexibilidad en el uso de las formas de pensamiento medio ambiental presentados, en razón de otros fenómenos sociales que también intervienen en niveles de gobernanza local. Ahondar en cómo el ambientalismo es asumido en el proceso de institucionalización del cambio climático, es de relevancia en la medida que determina las formas de gestión y convergencias públicoprivadas que repercuten en los municipios y que proyectan vulnerabilidades territoriales relacionadas con el fenómeno socio ambiental expuesto.

Como ejemplo de esto, el Estado no ha logrado superar la sobreexplotación de los recursos naturales y no ha propiciado un uso adecuado de bienes ecosistémicos como el agua. Aspectos que, son cuestionados desde el ecologismo social. La acción del Estado opera en principios contrapuestos (Blanco \& Fuenzalida, 2013); por un lado en la aplicación de políticas para dar cumplimiento a los acuerdos suscritos ante las reuniones internacionales de Naciones Unidas; y por otro, en el fomento a una economía de servicios verdes y continuadora de prácticas de neo extractivitas que se presenta incluso con criterios de sustentabilidad.

Por tanto, la particularidad que asume el ambientalismo en Chile permite que las políticas y regulaciones del Estado chileno se relacionen con algunas directrices de lo que en la literatura especializada se ha definido como Ambientalismo Neoliberal, el cual es conceptualizado como un medio de adaptación del libre mercado al medioambiente, en el entendido que la propiedad privada constituye 
Schlack Soto, M. F. (2019). Hacia un modelo de gestión local del cambio climático. Revista de Sociología, 34(1), 61-80. doi: 10.5354/0719529X.2019.54268

una forma de prevención y uso sustentable de los recursos naturales (Aldunate, 2001). Así, estas son estas condiciones las que como señala la evidencia empírica de este trabajo, estarían condiciendo los entendimientos de los funcionarios de los gobiernos locales integrantes de la Red Chilena de Municipios ante el Cambio Climático en la Región Metropolitana.

\section{MÉTODO}

El estudio que se presenta es cualitativo, en la medida que reconoce que la realidad es subjetiva y cambiante como resultado de la interacción entre sujetos y fenómenos sociales (Ortí, 1995). Tal descripción es acorde con la idea de que el cambio climático genera discursos. Por ello, el tipo de estudio fue exploratorio, porque se trabaja con un objeto poco estudiado y en proceso constante de construcción. De hecho, en la comprensión de la temática socioambiental, existe una tradición de estudios medioambientales desde la sociología, pero en lo relativo a la dimensión institucional y a los gobiernos locales integrantes de la Red Chilena de Alcaldes por el Cambio Climático se constató un vacío de conocimientos.

Los criterios de conformación de la muestra fueron teóricos, seleccionando a aquellos funcionarios o directores que por su conocimiento en la materia se desempeñaban en los departamentos ambientales de los municipios de la Región Metropolitana que integraban la Red hasta el año 2016. En total se realizaron 8 entrevistas las que fueron grabadas $\mathrm{y}$ transcritas. Los municipios en los cuales trabajan estos funcionarios se caracterizan por una diversidad socioeconómica y sus límites territoriales son tanto urbanos como rurales. Por tanto, se seleccionaron a los informantes calificados pertenecientes a las instancias ambientales de los siguientes municipios que aceptaron formar parte de la muestra: Calera de Tango, Colina, Independencia, La Pintana, Providencia, Peñalolén, Quilicura y Santiago. Desafortunadamente, los municipios de Lampa y Recoleta no mostraron interés en colaborar con este trabajo.

Técnica de producción de datos

La generación de datos se realizó por medio de entrevistas semiestructuradas con profesionales que ejercían su trabajo en los departamentos medio ambientales, los que fueron denominados como informantes claves. Ellos no constituyen una muestra fuera del rol técnico profesional que desempeñan y cada uno, en cuanto encarna dicho rol, resulta un informante clave para acceder a un fenómeno social en constante formación. La técnica de producción de información correspondió al modelo de entrevistas individuales abiertas semidirectivas, las cuales se estructuraron en función a los siguientes ejes narrativos y unidades de análisis: (a) representaciones locales sobre el cambio climático; (b) impactos locales del cambio 
Schlack Soto, M. F. (2019). Hacia un modelo de gestión local del cambio climático. Revista de Sociología, 34(1), 61-80. doi: 10.5354/0719529X.2019.54268

climático; (c) institucionalidad local y proyecciones; (d) prácticas de gobernanza local del cambio climático; y (e) cambio climático y crecimiento económico.

Para el análisis, se implementó la técnica del análisis de contenido, la cual facilitó la compresión de los discursos en el contexto mismo en que estos fueron construidos (Navarro \& Díaz, 1999). Lo anterior permitió la emergencia de las siguientes subcategorías procedentes del análisis descriptivo: desigualdad socioambiental, convergencias intrainstitucionales, adecuaciones institucionales y ambientalismo y ecologismo.

\section{RESULTADOS}

A partir de las impresiones emitidas de los informantes claves, se establecieron cuatro ejes de análisis discursivo sobre el cambio climático: (i) desigualdad socioambiental; (ii) convergencias intrainstitucionales; (iii) adecuaciones institucionales; $\mathrm{y}$ (iv) ambientalismo $\mathrm{y}$ ecologismo. La importancia de estos ejes emergentes es que pueden ordenar los discursos y permiten contextualizar las diversas impresiones sobre lo que constituye el fenómeno del cambio climático el grupo de gobiernos locales pertenecientes a la Red Chilena de Municipios ante el Cambio Climático.

\section{Desigualdad socio-ambiental}

Es la desigualdad el elemento que determina fuertemente las impresiones sobre el cambio climático que concretiza el especialista del Departamento de Educación Ambiental de la Municipalidad de la Pintana, dando cuenta así también de múltiples necesidades socioeconómicas:

"Cambio climático es una serie de eventos abruptos, que han generado respuestas de la sociedad civil y que las respuestas, lamentablemente, nos siguen recordando que hay una inequidad, pero salvaje" (Informante, Municipalidad de La Pintana).

También el cambio climático y su relación con la inequidad no está descrito únicamente hacia la limitada disponibilidad de recursos monetarios para abordar el cambio climático, sino que también a las condiciones estructurales de la comuna En este sentido, variables tales como el tipo de viviendas o las obras de vialidad pública, constituyen otros obstáculos para una adaptación efectiva a estos cambios ambientales:

"La Pintana estructuralmente está mucho menos preparada que una comuna que tiene recursos" (Informante, Municipalidad de la Pintana).

Para un municipio con múltiples carencias como el de La Pintana, los efectos del cambio climático y sus posibilidades para abordarlo están fuertemente determinas por la disposición de recursos municipales. De igual forma, la segregación socio-espacial que caracteriza a la Región Metropolitana, significa esto un potenciamiento de la desigualdad territorial el 
Schlack Soto, M. F. (2019). Hacia un modelo de gestión local del cambio climático. Revista de Sociología, 34(1), 61-80. doi: 10.5354/0719-

que está en directa relación con una mayor vulnerabilidad ante el cambio climático.

También en la Municipalidad de Colina, inserta en un contexto rural, emergieron impresiones sobre la desigualdad, las que fueron expuestas por la profesional de la Oficina de Gestión Ambiental Local. Exponiendo que las estrategias y los medios para abordar el cambio climático se encuentran diferenciados en concordancia con la disponibilidad de recursos con que cuentan los diversos gobiernos locales.

"En Vitacura se preocupan más del medio ambiente porque tienen resueltos todos los otros problemas, entonces ¿qué pasa en los municipios donde falta trabajo, falta esto o lo otro? En estos últimos el medio ambiente es un tema del que no se habla" (Informante, Municipalidad de Colina).

Ante tales impresiones, es necesario aclarar que el discurso de la informante clave no estuvo referido a que el cambio climático deba abordarse después de solucionar los problemas de trabajo o delincuencia. Lo que se sostuvo fue una reflexión sobre cómo la desigualdad incide en la conformación de las prácticas de gestión local relativas al cambio climático en contextos de carencias. Sin embargo, las impresiones comparativas en relación a una comuna con recursos como Vitacura deben ser analizadas críticamente, ya que, por ejemplo, comunas con altos índices de pobreza como La Pintana, han logrado desarrollar una gestión medio ambiental con alto impacto territorial.

También, la propensión a fenómenos extremos de temperatura producto del cambio climático se potencian en función de aspectos como la pobreza, intensificando las situaciones de vulnerabilidad, al respeto:

"El efecto calor es impresionante, porque nosotros tenemos sectores que, acá está la comuna, estos sectores, este y este, que tienen una pobreza extrema y una vulnerabilidad que es enorme, donde los impactos de los cambios climáticos, el calentamiento global, tanto en el extremo de la temperatura hacia arriba y hacia abajo, llegan aquí en forma despiadada" (Informante, Municipalidad de La Pintana).

Asimismo, en el discurso del especialista de la Municipalidad de La Pintana, se expone que los impactos que el cambio climático está generando en los territorios, otorgan un nuevo sentido para la acción ciudadana, y la vinculación de esta con los gobiernos locales, como dinámica de convergencia entre institución de gobierno y sociedad civil:

"Decirle a la gente, en el sentido de buscar alianzas con ellos, ha sido decirles que en la solución que se busca y se materializa ellos son protagonistas, que no pueden pasarse la vida tampoco pidiendo, ¿qué aprendimos con ello? Aprendimos que hay que conseguirse las cosas" (Informante, Municipalidad de La Pintana).

Convergencias intra-institucionales.

La carencia de los recursos hídricos constituye un problema común para los municipios insertos en áreas rurales y urbanas. Pero los efectos derivados de la falta de agua se han potenciado por la inexistencia de una convergencia 
Schlack Soto, M. F. (2019). Hacia un modelo de gestión local del cambio climático. Revista de Sociología, 34(1), 61-80. doi: 10.5354/0719529X.2019.54268

legislativa, que regule de mejor manera la distribución de este recurso ecosistemático. Con respecto a esto, el discurso del informante clave del Municipio de Calera de Tango sostuvo:

"A raíz del cambio climático, también aquí hay un alto crecimiento poblacional. Antes generalmente eran plantaciones en esta zona y ahora comenzaron a parcelarse y se están transformando en condominios, hay más poblaciones y es ciudad dormitorio, extraen el agua y así hay menos disponibilidad" (Informante, Municipalidad de Calera de Tango).

Desde el discurso de la especialista de la Municipalidad de Peñalolén se reafirma que la actual legislación que concibe al agua como un recurso transable en el mercado, aumenta los efectos que derivan del cambio climático, recalcando una evidente falta de convergencia entre las políticas nacionales del cambio climático y el uso jurídico que existe en Chile sobre el agua, y que ha operado así desde la dictadura cívico-militar:

"La reserva de nieve se mantenía en forma constante en la época estival, y hoy día ya está disminuyendo considerablemente, ya los derechos de agua, están vendidos.... Está vendida para la gente de la comunidad ecológica" (Informante, Municipalidad de Peñalolén).

Las impresiones revelan discursos que plantean que producto de los efectos del cambio climático, las poblaciones locales han requerido aumentar la profundidad de los pozos para obtener agua, siendo esto un problema que incide en el bienestar social. Esta realidad se ha potenciado en la medida que los permisos administrativos autorizados por la Intendencia Regional no están considerando la totalidad de los factores que potencian las consecuencias del cambio climático, dando cuenta esto, que la escasez hídrica se ha agudizado por la incapacidad de una institución mayor del Estado de articular mejores estrategias de convergencia intrainstitucional.

El discurso emanado desde el profesional del Departamento de Medio Ambiente de la Municipalidad de Quilicura reafirma lo señalado respecto de las débiles convergencias de la política nacional del Cambio climático:

"El Valle Lo Campino cada vez se construye más arriba, entonces, si no tienes vegetación, cada vez con una lluvia tienes allí el riesgo latente que pueda haber un aluvión o algo por el estilo que remueva materia y afecte a los vecinos" (Informante, Municipalidad de Quilicura).

En consecuencia, en el aumento de escenarios de escasez hídrica y en la proliferación de fenómenos climáticos extremos, el rol de la Intendencia Regional y el ministerio ha resultado contraproducente para la adaptación comunal al cambio climático. Como ejemplo de esto, desde algunos discursos analizados, el aumento de edificaciones y la presión de las inmobiliarias han potenciado las inundaciones y la escasez de agua que impacta en la producción agrícola, desde el municipio de Quilicura se señaló:

"La presión de la inmobiliaria, también, porque según la última actualización que se hizo al plan regulador de la Metropolitana 
Schlack Soto, M. F. (2019). Hacia un modelo de gestión local del cambio climático. Revista de Sociología, 34(1), 61-80. doi: 10.5354/0719529X.2019.54268

Santiago, la modificación, 100, todo nuestro territorio pasa a ser urbanizable; de expansión urbana como tal" (Informante, Municipalidad de Quilicura).

La situación antes descrita sobre la limitada disponibilidad de agua es compartida en el discurso del informante clave de la Municipalidad de Colina, donde la escasez de agua genera más situaciones de vulnerabilidad.

"Uno de los impactos es que, al haber menos agua, a los agricultores les sale mucho más caro regar, por lo tanto, muchos han vendido sus terrenos. Entonces ha disminuido el tema agrícola y, también, a nivel de comunidad hay muchas personas que reciben agua de pozo y el municipio les tiene que llevar agua porque no tienen el recurso, se han secado pozos" (Informante, Municipalidad de Colina).

Por consecuencia, los discursos emanados permiten aseverar que las limitadas convergencias intrainstitucionales existentes constituyen obstáculos que afectan las prácticas de gobernanza ambiental que los gobiernos municipales emprenden. Asimismo, las contradicciones presentadas aumentan los efectos adversos que el cambio climático genera en los territorios locales.

\section{Adecuaciones institucionales}

El eje analítico de "adecuación institucional" hace alusión a aquellos cambios organizacionales que se han realizado dentro de las oficinas medioambientales de los gobiernos locales. Estas oficinas operan como estamentos dentro de otra unidad municipal de mayor responsabilidad y alcance, como por ejemplo: la Dirección de Desarrollo Comunitario (DIDECO) o la Dirección de Medio Ambiente, Aseo y Ornato.

En el caso de la Municipalidad de Independencia, desde el discurso construido por el informante clave de la Oficina de Aseo y Ornato, se exponen las iniciativas que abordan el cambio climático. En este sentido, el discurso dio cuenta que un cambio institucional permitió trabajar las temáticas de cambio climático:

"Quien vio la necesidad de participar en todas las iniciativas que tienen que ver con el cambio climático. Aquí se fortaleció todas las acciones que tienen que ver con las políticas medio ambientales. El Departamento Medio Ambiental se creó con la llegada del alcalde, Gonzalo Durán, 2013- 2014 y una de las primeras tareas fue tratar de trabajar en todas las temáticas que pudieran influir en el cambio climático" (Informante, Municipalidad de Independencia).

De los contenidos manifiestos del discurso, también se manifestó una valoración positiva sobre lo que ha sido el Departamento de Ornato y Gestión Medio ambiental, exponiendo que tal adecuación institucional permitió contar con capital humano que hace posible una mejor gestión local del cambio climático:

"Se creó el Departamento de Medio Ambiente, que antes no existía. Había solamente una persona que se dedicaba al tema de paisajismo, ornato, medio ambiente y hoy día no, pues. Es un departamento estructurado, donde hay un profesional a cargo" (Informante, Municipalidad de Independencia). 
Schlack Soto, M. F. (2019). Hacia un modelo de gestión local del cambio climático. Revista de Sociología, 34(1), 61-80. doi: 10.5354/0719529X.2019.54268

Por otro lado, en gobiernos locales donde las unidades de medio ambientales no son estructuras autónomas, también se han llevado a cabo acciones ambientales que permiten abordar transversalmente el cambio climático. En el discurso del profesional del gobierno local de Quilicura se aprecia un discurso que destaca la integración del abordaje del cambio climático entre diversas oficinas municipales:

"El director, por petición, hizo que tratáramos de incluir este concepto de cambio climático en todos los quehaceres municipales" (Informante, Municipalidad de Quilicura).

En el caso de la Municipalidad de Providencia, el cambio climático también se gestiona desde un Departamento Medio Ambiente, Aseo y Ornato (DAOM), en el que su director debe coordinar también las responsabilidades tradicionales de mantención del aseo en Providencia (DAOM). Sin embargo, el Departamento se ha caracterizado por la ampliación de su planta profesional:

"El Departamento de Medio Ambiente creció en personas...se creó el nuevo cargo que yo ocupo, el de coordinador de energía, que es un cargo institucional" (Informante, Municipalidad de Providencia).

El cargo de Coordinador de Energía constituye una adecuación institucional, según el discurso de la informante de la Municipalidad de Providencia, el cual ha facilitado realizar también auditorías energéticas para reducir la energía consumida y proyectar acciones de abordaje del cambio climático. Las prácticas locales de coordinación entre unidades municipales son descritas como un ejemplo de transversalidad. Esto hace referencia también a una marcada valoración sobre la gestión climática local que existe en la municipalidad de Providencia, haciendo alusión sin embargo a los efectos adversos que para una gestión de gobernanza local significan las restricciones que presenta la ley Orgánica Constitucional Municipal $\mathrm{N}^{\circ}$ 18.695:

"Es que en Providencia el cambio climático se ha tomado de una manera transversal. $\mathrm{O}$ sea, si bien no ha sido específica, diciendo: "oh sí el cambio climático", pero sí siempre ha ido a la vanguardia y siempre ha estado vinculada en temas de gestión del Carbono, en mediciones de huellas de Carbono, con todas las limitaciones que nos da la Ley General de Municipalidades" (Informante, Municipalidad de Providencia).

Es necesario señalar que tal legislación es el instrumento que define tanto las responsabilidades, así como determina el funcionamiento interno de los gobiernos locales en Chile. A pesar de sus sucesivas modificaciones, la ley es constantemente objeto de críticas debido a los obstáculos que provoca para mejorar la gestión municipal en todas sus áreas.

A su vez, se identifican ciertas similitudes en los discursos emitidos por los informantes de los municipios de Providencia y Santiago respecto de la Ley Orgánica Constitucional Municipal $\mathrm{N}^{\circ}$ 18.695. Sin embargo, en el discurso que se presenta a continuación, no hay una referencia explícita a tal ordenamiento jurídico, pero interpretativamente se desprende una referencia al mencionado cuerpo legal: 
Schlack Soto, M. F. (2019). Hacia un modelo de gestión local del cambio climático. Revista de Sociología, 34(1), 61-80. doi: 10.5354/0719529X.2019.54268

"Es tanta la demanda del día a día que uno no se detiene a atender temas nuevos y el tema del cambio climático es un tema nuevo" (Informante, Municipalidad de Santiago).

Lo anterior se justifica en función de que la ley en cuestión, en sus modificaciones, sólo ha incluido la obligación de gestionar localmente el medio ambiente, pero no hay referencias al cambio climático, debido probablemente a su novedad. Ahora bien, los obstáculos institucionales de sistema municipal se relacionan con impresiones críticas hacia todo el sistema público.

Con respeto a la comuna de La Pintana, el modelo de gestión en este ha sido objeto de estudio y de referencia como ejemplo de efectividad en la concreción de políticas de medio ambiente en un contexto de carencia. Tal realidad fue valorada en el discurso del informante calificado del municipio. Los contenidos del discurso emanado por el informante clave de la Municipalidad de La Pintana permiten comprender que el modelo de gestión ambiental construido por este gobierno local es representado en forma altamente positiva, revelando un sentido de orgullo ante el trabajo de adecuación institucional desarrollado:

"Porque nosotros estamos desde el año 94 haciendo gestión ambiental, con la claridad de la gestión ambiental local y con la claridad de lo que significa el medio ambiente en la función antrópico urbana" (Informante, Municipalidad de La Pintana).

Como se demuestra en el discurso, ha sido el Municipio de La Pintana, la primera institución de gobierno local que desarrolló un modelo de gestión ambiental territorial, en el cual se elaboraron programas de educación ambiental y de reciclaje. Este proceso es factible de caracterizarlo como dinamismo institucional y corresponde a un modo de adecuación que cuenta con años de desarrollo y que alude a las diversas etapas que se han ideado y concretado desde este municipio a través de su Dirección de Gestión Municipal. En concordancia con lo expuesto:

"El año 2008 fue el año en que nosotros registramos esto, pero nosotros venimos con una gestión ambiental orientada en el cambio global y, específicamente, en el foco del calentamiento global" (Informante, Municipalidad de La Pintana).

El modelo de gestión climática local que ha operado desde este Municipio fue representado e identificado por el informante clave como referencial. Es decir, el contenido discursivo también se construye como una referencia a lo que han sido los procesos de adecuación institucional en otros municipios:

"Claro, somos un referente, somos un modelo" (Informante, Municipalidad de la Pintana). Los discursos que se presentarán a continuación dan cuenta de una mayor transformación de los modos de trabajo y organización municipal para abordar el cambio climático. Por tanto, el eje analítico que emerge lo hemos denominado "Nueva Unidad", siendo esta una forma distinta de adecuación institucional. Tal cambio trata sobre los gobiernos municipales que han creado una unidad específica para abordar los asuntos de medio ambiente y cambio climático. Se trata del municipio de Peñalolén, el que ha ideado y puesto en práctica esta reforma institucional. 
Schlack Soto, M. F. (2019). Hacia un modelo de gestión local del cambio climático. Revista de Sociología, 34(1), 61-80. doi: 10.5354/0719-

Así, este municipio cuenta con un departamento con director de servicio exclusivo para la gestión climática local, lo que desliga las responsabilidades sobre los quehaceres municipales de aseo y ornato $\mathrm{u}$ otros servicios.

"Nosotros, a diferencia de otras municipalidades que dentro de la Dirección de Operaciones tiene los departamentos de Aseo y Ornato, por ejemplo y dentro de este se incluye Medio Ambiente; acá, Medio Ambiente tiene su dirección propia" (Informante, Municipalidad de Peñalolén).

Por tanto, la adecuación institucional conformada responde a una reflexión sobre los impactos positivos que significa el contar con un director propio para el departamento. Las ventajas de esta forma de concretar los cambios institucionales permiten sortear las estructuras burocráticas existentes en los municipios. Al respecto:

"A diferencia de otros lados donde dentro de un área de un departamento el tema burocrático es más largo y lento, aquí, es más directo" (Informante, Municipalidad de Peñalolén).

Como se aprecia en el discurso presentado, la existencia de un departamento medio ambiental independiente y no subordinado a otra instancia municipal, es reconocida como un factor que posibilita un trabajo directo con la Alcaldía. Esta adecuación institucional es, asimismo, reconocida y valorada por las ventajas que conlleva para una gestión local del cambio climático:

"Lo prioriza más, lo jerarquiza más dentro de la toma de decisiones. No es simplemente una colita dentro de muchas otras colitas dentro de una dirección, sino que es un tema concreto, un pilar" (Informante, Municipalidad de Peñalolén).

Sobre las ventajas de contar con un departamento medio ambiental no subordinado, es que se posicionan de mejor manera las temáticas medio ambientales como es el cambio climático en la gestión local.

\section{Ambientalismo y Ecologismo}

En el análisis de los discursos construidos por los informantes claves de los Municipios, se identificaron lineamientos relativos al ambientalismo y al ecologismo, lo que permite sostener una tensión entre las formas que cada uno propone para enfrentar el cambio climático. En mención a lo expresado, los discursos de los profesionales de los Municipios de Colina, Calera de Tango, Peñalolén e Independencia articularon una concepción más cercana a las ideas de favorecer el crecimiento económico como generador de condiciones para contribuir a la disminución de las emisiones de efecto invernadero. Esto permite aseverar que sus representaciones se estructuran en concordancia con los lineamientos del ambientalismo:

"Yo creo que a mayor crecimiento económico y si se ingresan las políticas necesarias, si se puede contribuir a la disminución de gases de efecto invernadero" (Informante, Municipalidad de Colina).

El crecimiento económico también fue comprendido como propicio para superar las necesidades de carencia, en cuanto que una 
Schlack Soto, M. F. (2019). Hacia un modelo de gestión local del cambio climático. Revista de Sociología, 34(1), 61-80. doi: 10.5354/0719-

sociedad satisfecha económicamente constituye un paso previo para que se instauren las preocupaciones sobre el cambio climático:

"Entonces la gente que tiene mayor poder económico puede dar cabida a otras variables que tengan algún poder adquisitivo y que no sean de las primarias" (Informante, Municipalidad de Peñalolén).

En contraposición con estas valoraciones del crecimiento económico como compatible con un abordaje del cambio climático, algunos discursos municipales presentaron aspectos que se han difundido desde las ideas acordes con el ecologismo. En este sentido, la disminución del consumo humano se propone como manera de reducir las dinámicas de crecimiento económico identificadas estas como uno de los elementos de la crisis ecológica del planeta:

"Veamos lo que necesitamos, vivamos bien, no vivamos para consumir consumamos lo necesario para vivir" (Informante, Municipalidad de Santiago).

Asimismo, desde el discurso de la informante de la municipalidad de Santiago se muestra un discurso crítico respecto de las sugerencias emanadas desde el Estado chileno y de las instituciones internacionales sobre cambio climático que postulan abordar el cambio climático a través de los instrumentos de una Economía Verde. Siendo esta perspectiva propia de una corriente de pensamiento ambientalista, al respecto:

"¿Qué tenemos que hacer los municipios ahí?... salvo enterarnos que esto está ocurriendo, porque nosotros no generamos acciones ni comercializamos acciones a través del Carbono. Y cuáles fueron los acuerdos tecno políticos que se generan en las cumbres en Marraquech o antes, pero eso para nosotros está lejos, lejos" (Informante, Municipalidad de Santiago).

Asimismo, el discurso emanado desde el profesional de la municipalidad de la Pintana proyecta impresiones sobre la necesidad de protección y conservación de la naturaleza, como aspectos de preponderancia de la relación sociedad-naturaleza. Asimismo, en sus impresiones sobre la disminución de los efectos del cambio climático y la compatibilidad con el crecimiento económico, desde los gobiernos municipales de Santiago y La Pintana, surgieron valoraciones sobre el desarrollo como un concepto que puede reemplazar al de crecimiento económico:

"Pero estamos diciendo a la gente que tiene desarrollo como seres humanos, le estamos diciendo que la humanidad tiene que conservar el respeto por la naturaleza" (Informante, Municipalidad de La Pintana).

Con respecto a este discurso, surgieron dos afirmaciones que se presentaron relacionadas: estas son el respeto a la naturaleza y el desarrollo:

"Incorporar tecnología que gasten menos energía y que sean más eficiente y más sustentables, eso, sí o sí genera mayor desarrollo económico" (Informante, Municipalidad de Santiago).

Si bien tales impresiones dieron cuenta de preponderancia del desarrollo económico por sobre crecimiento económico, sí existe un discurso emanado desde la especialista de la 
Schlack Soto, M. F. (2019). Hacia un modelo de gestión local del cambio climático. Revista de Sociología, 34(1), 61-80. doi: 10.5354/0719529X.2019.54268

Municipalidad de Santiago sobre la compatibilidad entre crecimiento económico y disminución de las emisiones de gases de efecto invernadero:

"Crecimiento económico, claro. Si yo hago mejor las cosas con criterios ambientales, tengo menos efecto y por supuesto que me va a ir mejor" (Informante, Municipalidad de Santiago).

Por consecuencia, en estos discursos que construyeron una impresión crítica sobre el crecimiento económico, también es identificable una contradicción, la cual está explícita en el contenido discursivo presentado por la profesional de Municipio de Santiago. Entonces, las discursividades presentadas permiten aseverar que, para la mayoría de los municipios, el cambio climático es entendido desde los parámetros del Ambientalismo. Sin embargo, como se demostró, se reconocen algunos principios propios del ecologismo en los discursos emitidos de los municipios de Santiago y La Pintana.

\section{DISCUSIÓN Y CONCLUSIONES}

El cambio climático fue representado como un asunto complejo y con múltiples características para los informantes claves de los gobiernos locales integrantes de la Red Chilena de Municipios ante el Cambio Climático. En este sentido, las impresiones de actores claves de los municipios permitieron demostrar que existen variadas visiones sobre las implicancias del fenómeno climático: algunas fueron coincidentes entre varios municipios, otras demostraron la tensión existente entre las diferentes realidades municipalidades y otras mostraron contradicciones presentes en un mismo discurso sobre la compatibilidad entre crecimiento económico y disminución de los gases de efecto invernadero.

Los resultados permiten señalar que la desigualdad es un aspecto de marcada trascendencia en un municipio caracterizado por la carencia económica como el de la comuna de la Pintana. Por tanto, el abordaje del cambio climático que realice la sociología debe considerar la carencia como factor de trascendencia y que tal condición puede determinar las posibilidades de convergencias intrainstitucional.

El cambio climático para los informantes claves insertos en municipios rurales se comprendió en relación a la escasez de un elemento ecosistémico como es el agua. Esta carencia de agua se relaciona con que su uso, en muchos casos, depende de los ingresos socioeconómicos de los habitantes. En el caso de la municipalidad de Peñalolén, pese a no ser esta una comuna rural ni carenciada, los efectos de la escasez hídrica se potencia puesto que en Chile prima un régimen jurídico que concibe al agua como un bien privado, indicando esto, que los lineamientos neoliberales existentes en la actualidad son obstáculos para los planes locales de abordaje del cambio climático. Por ello, las estrategias de convergencia entre instituciones públicas y 
Schlack Soto, M. F. (2019). Hacia un modelo de gestión local del cambio climático. Revista de Sociología, 34(1), 61-80. doi: 10.5354/0719529X.2019.54268

privadas son débiles, y el Estado enfrenta una contradicción en la medida que a nivel discusivo ha señalado que el cambio climático constituye una prioridad, pero no es capaz de regular un elemento trascendental como el agua en el marco de una sociedad altamente vulnerable al cambio climático.

También la débil convergencia intrainstitucional indica que los efectos locales del cambio climático para los gobiernos locales se agudizan en razón de aspectos tales como la regulación urbana, el uso del suelo o los permisos de edificación. Esto demuestra que muchos planes de cambio climático que se han generado desde el gobierno central requieren de mayor participación de los municipios. En este sentido, la gobernanza ambiental puede ser un ejercicio de fomento a una democracia participativa. Por tanto, la gobernanza del cambio climático a nivel local está siendo afectada por la falta de participación de los municipios. Futuros estudios debiesen generar conocimientos sobre cómo idear estrategias contra el cambio climático, basadas en criterios de convergencia y mayor democratización en los aspectos de Estado.

Con respecto a los cambios institucionales que han realizado los gobiernos locales se reconoce que éstos cuentan con una capacidad de reflexividad, permitiendo así evaluar sus mismas estructuras municipales. Sin embargo, la reflexividad no se presentó como una facultad homogénea, en la medida que cada ejercicio de reflexividad tomó forma en base a las características propias de cada municipio y sus respectivos territorios administrados. En relación con esto, la Municipalidad de Peñalolén ha conformado una unidad ambiental desligada de las labores de aseo y ornato, la cual establece una comunicación más directa de los asuntos de cambio climático con la Alcaldía. Los beneficios de estas modificaciones institucionales radican en el fortalecimiento de la gestión ambiental, puesto que se cuenta con un director de servicios y puede interceder directamente en las reuniones de los Consejos Municipales, logrando una priorización del tema climático en la gestión municipal. Sin embargo, en el caso de las otras comunas de la muestra, la no existencia de un director de medio ambiente desligado de las gestiones de aseo y ornato no constituyó un obstáculo para que las restantes municipalidades aborden el cambio climático.

En este trabajo de investigación, se señaló que las maneras de comprender un problema socioambiental como el cambio climático son determinadas por las concepciones relativas al ecologismo y al ambientalismo. El análisis de los discursos de los municipios también demostró que las impresiones sobre el cambio climático y su relación con aspectos tales, como el crecimiento económico y la reducción de los gases de efecto invernadero también han sido determinados por los parámetros de tales corrientes de pensamiento socio ambiental. Para un municipio como el de La Pintana, en la compresión sobre el cambio climático, existen aspectos que están en concordancia con la descripción efectuada por el ecologismo. Es decir, que los daños al medio ambiente extienden las experiencias de injustica social y demuestran que los efectos varían en función de situaciones de clase. 
Schlack Soto, M. F. (2019). Hacia un modelo de gestión local del cambio climático. Revista de Sociología, 34(1), 61-80. doi: 10.5354/0719529X.2019.54268

Desde las ideas del Ecologismo, se sostiene que la superación de una crisis como el cambio climático requiere de las transformaciones de las acciones sociales y de las representaciones culturales sobre la naturaleza. En relación con esto, algunos de los gobiernos locales expresaron la necesidad de concretar tales dinámicas de modificación social y cultural. Sin embargo, la presencia de discursos que apelan a estas ideas no puede entenderse como una identificación total a los sustentos de la corriente de pensamiento señalada, ya que como se demostró en el análisis sobre la compatibilidad entre el aumento del crecimiento económico y la reducción de los gases de efecto invernadero, para algunos discursos, la generación de crecimiento económico es propicia para lograr una disminución de los gases de efecto invernadero. Vale decir, son más cercanos a un pensamiento ambientalista.

En los discursos emitidos por los informantes claves de las municipalidades de Santiago y La Pintana, existe un cuestionamiento y una deslegitimización hacia las prácticas sociales y culturales que han propiciado la existencia de una crisis como el cambio climático. Aquellas impresiones identificadas en función de la orientación ecologista entran en contradicción con las ideas que estos dos municipios construyeron sobre la compatibilidad de aumentar el crecimiento económico como un medio para superar los problemas del cambio climático. El análisis de tales orientaciones constituye una evidente tensión, ya que ha sido desde el ambientalismo desde el cual se ha sostenido que la protección de la naturaleza es factible con los lineamientos del sistema capitalista. En relación con esto, son necesarias otras investigaciones que profundicen en el choque entre las variadas significaciones sobre estas dos formas de compresión de la relación sociedad-naturaleza, para así revelar qué significado tienen conceptos como modernización y cambio cultural en el contexto de una sociedad vulnerable al cambio climático.

Por otra parte, las municipalidades analizadas están siendo guiadas por alcaldes con identificaciones políticas tanto de la Ex Nueva Mayoría como de la Alianza por Chile, sin embargo, no fueron identificables aquellas corrientes de pensamiento que, como en Estados Unidos, han relativizado y negado que las acciones humanas sean los factores que aceleren el cambio climático. Lo anterior demuestra que incluso en los discursos de partidos políticos que apelan a directrices neoliberales en Chile, el Ambientalismo en su arista más radical, no tiene cabida.

Lo señalado hace factible considerar la relevancia de realizar investigaciones que indaguen sobre cómo los gobiernos locales dirigidos por ediles de los partidos de derecha entran en tensión con muchas de las ideas que, desde sus sectores políticos, promueven una menor regulación de las actividades económicas. Esto demuestra que el cambio climático debe ser abordado por una sociología cuyo enfoque sea concretamente el cambio climático y las relaciones que se establecen con otros fenómenos como las ideologías políticas, la educación y las formas de consumo de una sociedad compleja como la chilena, la que requiere nuevas formas 
Schlack Soto, M. F. (2019). Hacia un modelo de gestión local del cambio climático. Revista de Sociología, 34(1), 61-80. doi: 10.5354/0719529X.2019.54268

de entendimiento sobre la relación sociedadnaturaleza para así contribuir a reducir las emisiones de gases de efecto invernadero que aceleran el proceso de calentamiento global.

\section{REFERENCIAS}

Aldunate, C. (2001). El factor ecológico: Las mil caras del pensamiento verde. Santiago de Chile: LOM Ediciones.

Aliste, E. (2010). Territorio y ciencias sociales: Trayectorias espaciales y ambientales en debate. En E. Aliste \& A. Urquiza (Ed.), Medio ambiente y sociedad (pp. 55-76). Santiago de Chile: Ril Editores.

Aliste, E. \& Stamm, E. (2016). Hacia una geografía de los conflictos socioambientales en Santiago de Chile: Lecturas para una ecología política del territorio, Revista de Estudios Sociales, 55, 55-62. doi: 10.7440/res55.2016.03

Arnold, M. \& Urquiza, A. (2010). Las amenazas ambientales: Una visión desde la teoría de los sistemas sociopoiéticos. En E. Aliste 6 A. Urquiza (Ed.), Medio ambiente y sociedad (pp. 55- 76). Santiago de Chile: Ril Editores.

Beck, U. (1998). La sociedad del riesgo. Hacia una nueva modernidad. Barcelona, España: Paidós.

Beck, U. (2008). La sociedad del riesgo mundial. En busca de la seguridad perdida. Barcelona, España: Paidós.

Blanco, G. \& Fuenzalida, M. (2013). La construcción de agendas científicas sobre cambio climático y su influencia en la territorialización de políticas públicas: reflexiones a partir del caso chileno. En J.C. Postigo (Ed.), Cambio climático, movimientos sociales y políticas públicas. Una vinculación necesaria. (pp. 77-102). Santiago de Chile: ICAL.

De Castro, F., Hogenboom B., \& Baud, M. (2015). Gobernanza Ambiental en América Latina en la encrucijada. Moviéndose entre múltiples imágenes, interacciones e instituciones. En F. de Castro, B.
Hogenboom, \& M. Baud (Coord.), Gobernanza Ambiental en América Latina (pp. 13-38). Buenos Aires, Argentina : CLACSO.

Dobson, A. (1997). Pensamiento político verde. Barcelona, España: Paidós.

Fernández, J. (2010). Gestión ambiental local. En Ministerio del Medio Ambiente (Ed.), ¿Hacia dónde va la gestión ambiental local? aportes y sugerencias pensando en Río+20 (pp. 62-95). Santiago: Gobierno de Chile.

Giddens, A. (2010). La política del cambio climático. Madrid, España: Alianza Editorial.

Gudynas, E. (2011). El nuevo extractivismo progresista en América del Sur. Tesis sobre un viejo problema bajo nuevas expresiones. En A. Acosta, E. Gudynas, \& F. Houtart. (Eds.), Colonialismos del siglo XXI. Negocios extractivos y defensa del territorio en América Latina (pp.75-92). Barcelona, España: Icaria Editorial.

Intergovernmental Panel on Climate Change. (2018). Summary for policymakers, global warming of $1,5^{\circ}$. Recuperado de www.ipcc.ch

Navarro, P. \& Díaz, C. (1999). Análisis de Contenido. En J.M. Delgado y J. Gutiérrez (Eds.), Métodos y técnicas cualitativas de investigación en ciencias sociales (pp. 177224). Madrid, España: Editorial Síntesis

Ortí, A. (1995). La apertura y el enfoque cualitativo estructural: La entrevista y la discusión de grupo. En F. García, J. Ibáñez y F. Alvira (Comp.), El análisis de la realidad social, métodos y técnicas de investigación (pp.153-186). Madrid, España: Editorial Alianza.

Riechmann, J \& Fernández Buy, F. (1994). Redes que dan libertad: Introducción a los nuevos 


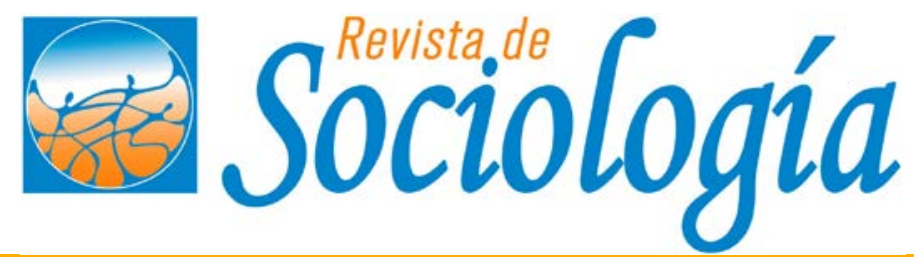

movimientos sociales. Barcelona, España: Paidós

Rungruangsakorn, C. \& Jara, C. (2012, Mayo). Gestión ambiental local: Una aproximación al estado del arte en Chile. Articulo presentado al Congreso Latinoamericano de Prevención de Riesgos y Medio Ambiente,
Schlack Soto, M. F. (2019). Hacia un modelo de gestión local del cambio climático. Revista de Sociología, 34(1), 61-80. doi: 10.5354/0719529X.2019.54268

Manuscrito recibido: 30-04-2019

Manuscrito aceptado: 31-07-2019 http://congresopryma.blogutem.cl/memorias 